\title{
Effect of shRNA-mediated knockdown of vascular endothelial growth factor on the proliferation of choroid-retinal endothelial cells under hypoxic conditions
}

\author{
AI-HUA LIU, JING SUN，YI SHI，GUO-LING SUN and HONG ZHANG \\ Department of Glaucoma and Fundus Diseases, Tianjin Medical University Eye Hospital, Tianjin 300384, P.R. China
}

Received August 25, 2014; Accepted May 15, 2015

DOI: $10.3892 / \mathrm{etm} .2015 .2596$

\begin{abstract}
The aim of the present study was to investigate the role of vascular endothelial growth factor (VEGF) in cell proliferation under hypoxic conditions. Gene knockdown of VEGF was conducted in the choroid-retinal endothelial RF/6A cell line by transfection with short hairpin RNA (shRNA), in which a shRNA fragment against VEGF was synthesized and cloned into the vector, pSilencer 2.1-U6 neo. Subsequently, a model of hypoxia was established in the RF/6A cell line via treatment with $\mathrm{CoCl}_{2}$, into which the recombinant plasmids, containing the VEGF-targeting shRNA (p-shRNA), were transfected. The study included four treatment groups, namely a control group (normal group), a hypoxia group treated with $\mathrm{CoCl}_{2}\left(\mathrm{CoCl}_{2}\right.$ group), a control plasmid group that were subjected to $\mathrm{CoCl}_{2}$ treatment and transfection with a pSilencer 2.1-U6 neo plasmid without the shRNA $\left(\mathrm{CoCl}_{2}+\mathrm{p}-\mathrm{NC}\right.$ group$)$, and a group treated with $\mathrm{CoCl}_{2}$ and transfected with a pSilencer 2.1-U6 neo plasmid containing the VEGF-targeting shRNA $\left(\mathrm{CoCl}_{2}+\mathrm{p}\right.$-shRNA group). Subsequent to treatment, the mRNA and protein expression levels of VEGF were evaluated using quantitative polymerase chain reaction and western blot analysis, respectively, In addition, cell proliferation was assessed. RF/6A cells treated with $\mathrm{CoCl}_{2}$ reduced cell connectivity, irregular morphology and reduced thickness compared with the cells in the normal group. However, cells in the $\mathrm{CoCl}_{2}+$ p-shRNA group exhibited an improved morphology compared with the $\mathrm{CoCl}_{2}$ and $\mathrm{CoCl}_{2}+\mathrm{p}-\mathrm{NC}$ groups. Cell proliferation in the $\mathrm{CoCl}_{2}$ group was enhanced in a time-dependent manner. However, the hypoxia-induced increase in cell proliferation was significantly inhibited in the $\mathrm{CoCl}_{2}+\mathrm{p}$-shRNA group, with inhibition rates of 16,32 and $38 \%$ at 24,48 and $72 \mathrm{~h}$, respectively. The mRNA and protein expression levels of VEGF were increased in the
\end{abstract}

Correspondence to: Dr Hong Zhang, Department of Glaucoma and Fundus Disease, Tianjin Medical University Eye Hospital, 251 Fukang Road, Tianjin 300384, P.R. China

E-mail: hongzhang4043@163.com

Key words: vascular endothelial growth factor, short hairpin RNA, retinal neovascularization diseases, $\mathrm{CoCl}_{2}$, cell proliferation
$\mathrm{CoCl}_{2}$ group when compared with the normal group, and these hypoxia-induced increases in VEGF expression were reduced in the $\mathrm{CoCl}_{2}+\mathrm{p}$-shRNA group. Therefore, the results indicated that the targeted knockdown of VEGF in vascular endothelial cells may be effective for the treatment of retinal neovascularization diseases.

\section{Introduction}

Retinal neovascularization diseases, such as proliferative diabetic retinopathy (DR), retinopathy of prematurity (ROP) and secondary neovascular glaucoma, may be caused by a variety of angiogenic factors in the retinal tissue under ischemic and hypoxic conditions, leading to the generation of new blood vessels. Retinal neovascularization is a complex process and involves the participation of a variety of angiogenic cytokines, including basic fibroblast growth factor, platelet-derived growth factor (1), epidermal growth factor (2), hepatocyte growth factor (3), tumor necrosis factor and vascular endothelial growth factor (VEGF). Among these, VEGF has been considered to be the most important factor (4). Previous studies have indicated that VEGF expression levels are significantly increased in tissues with DR (5), ROP (6) and other retinal neovascularization diseases, indicating that VEGF is a key factor in the promotion of angiogenesis.

Since VEGF is able to significantly promote angiogenesis, the growth factor may provide a target for the prevention and treatment of angiogenesis-associated diseases. Inhibitors for VEGF include anti-VEGF antibodies (such as bevacizumab, a recombinant human VEGF antibody) (7), soluble VEGF receptors (such as pegaptanib, a VEGF-165 RNA antagonist) (8), VEGF receptor antagonists, antisense VEGF (9) and VEGF-associated signal pathway inhibitors. Although these drugs may be useful for the inhibition of retinal neovascularization, and a number of these drugs have been used in a clinical context, one issue with their application is the requirement for frequent administration in order to maintain a suppressive effect against VEGF. Thus, the identification of VEGF inhibitors with longer lasting effects, as compared with the aforementioned drugs, is necessary.

RNA interference (RNAi) is a post-transcriptional gene-silencing mechanism that can be initiated by a double-stranded RNA (dsRNA) homologous in sequence to 
the targeted gene, which induces cells to present a specific gene deletion phenotype (10). RNAi has previously been used for the functional analysis of genes in invertebrates, plants and mammals (11). In the present study, a recombinant pSilencer 2.1-U6 neo plasmid was constructed containing short hairpin RNA (shRNA) targeted against the eucaryotic VEGF gene. The recombinant plasmid was subsequently transfected into a monkey choroid-retinal endothelial cell line (RF/6A). The effects of the plasmid on the mRNA and protein expression levels of VEGF and on the proliferation of the RF/6A cell line were evaluated.

\section{Materials and methods}

Construction of the pSilencer 2.1-U6 neo-shRNA plasmid. A 21-mer short hairpin RNA (shRNA) against VEGF mRNA (GenBank accession no. NM_001089925) was designed. According to the targeting sequences, two pairs of 66-mer oligonucleotides coding the shRNA were designed. The shRNAs were manufactured by Santa Cruz Biotechnology, Inc. (Santa Cruz, CA, USA). Each shRNA sequence contained a 7-bp loop sequence that separated the two complementary domains. The $3^{\prime}$ end of the shRNA template was a 5-nucleotide poly (T) tract recognized as an RNA Pol III termination signal, while the 5' ends of the two oligonucleotides contained BamHI and HindIII restriction site overhangs. The sequence for the complete VEGF shRNA insert template was as follows (lower case indicates an inverted repeat sequence): 5'-GATCCCgaa gagaaggaagaagagaggTCAAGAGCCTCTCTTCTTCCTTCT CTTCTTTTTTGGAAA-3' (sense) and 5'-AGCTTTTCC AAAAAAgaagagaaggaagaagagaggCTCTTGACCTCTCTT CTTCCTTCTCTTCGG-3' (antisense). These oligonucleotides were synthesized, annealed and ligated into the BamHI and HindIII sites of the pSilencer 2.1-U6 neo shRNA vector (Ambion Life Technologies, Carlsbad, CA, USA) using T4 DNA ligase (Takara Bio, Inc., Otsu, Japan) (Fig. 1), as described in a previous study (12). The recombinant vectors were transformed into Escherichia coli XL1-Blue, and positive clones were selected using ampicillin (Sigma-Aldrich, St. Louis, MO, USA) and identified using BamHI and HindIII restriction and DNA sequencing (Invitrogen Life Technologies, Grand Island, NY, USA). A negative control plasmid, pSilencer 2.1-U6 neo-NC (p-NC), was supplied by Ambion Life Technologies.

Cell culture and transfection. RF/6A cells were cultured in RPMI 1640 medium (Invitrogen Life Technologies, Grand Island, NY, USA), supplemented with $10 \%$ fetal bovine serum (FBS) and $1 \%$ penicillin/streptomycin (HyClone; GE Healthcare Life Sciences, Logan, UT, USA), at $37^{\circ} \mathrm{C}$ in $5 \% \mathrm{CO}_{2}$ and $95 \%$ humidified air. The $\mathrm{RF} / 6 \mathrm{~A}$ cells were divided into four groups, which included the normal group, $\mathrm{CoCl}_{2}$ group, $\mathrm{CoCl}_{2}$ plus negative control vector transfection $\left(\mathrm{CoCl}_{2}+\mathrm{p}-\mathrm{NC}\right)$ group, and the $\mathrm{CoCl}_{2}$ plus VEGF-targeting shRNA vector transfection $\left(\mathrm{CoCl}_{2}+\mathrm{p}\right.$-shRNA) group. The cells treated with $\mathrm{CoCl}_{2}$ were exposed to $100 \mu \mathrm{mol} / 1 \mathrm{CoCl}_{2}$ (Sigma-Aldrich) for $24 \mathrm{~h}$ in order to induce a model hypoxic response. Subsequently, the RF/6A cells were seeded onto 24 -well plates at a density of $2.0 \times 10^{5}$ cells/well and cultured for $24 \mathrm{~h}$. The recombinant pSilencer 2.1-U6 neo-shRNA vector and the negative control pSilencer 2.1-U6 neo-NC vector were transfected into the RF/6A cells using Lipofectamine ${ }^{\mathrm{TM}} 2000$ (Invitrogen Life Technologies).

Reverse transcription quantitative polymerase chain reaction ( $q P C R)$. Total cellular RNA was extracted from the cells using TRIzol reagent (Invitrogen Life Technologies) and quantified using UV absorbance spectroscopy (NanoDrop 2000 spectrophotometer; Thermo Fisher Scientific, Waltham, MA, USA) and $1.2 \%$ agarose formaldehyde gels. Reverse transcription was performed using an ExScript ${ }^{\mathrm{TM}} \mathrm{RT}$ reagent kit (Takara Bio, Inc.). Subsequently, the real-time experiments were conducted using an ABI PRISM 7300 sequence detection system and SYBR Green Real-time PCR Master Mix (Applied Biosystems Life Technologies, Beijing, China). The thermal cycling conditions for the PCR assay consisted of an initial denaturation step for $30 \mathrm{sec}$ at $95^{\circ} \mathrm{C}$, followed by 40 cycles at $95^{\circ} \mathrm{C}$ for $10 \mathrm{sec}, 60^{\circ} \mathrm{C}$ for $30 \mathrm{sec}$ and $72^{\circ} \mathrm{C}$ for $30 \mathrm{sec}$. The sequences of the PCR primers were as follows: VEGF, $5^{\prime}-\mathrm{ACT}$ CTTCCCACAGGCATCAG-3' (sense) and 5'-CCCTATCCC ATTCTTGCCTAT-3' (antisense); GAPDH, 5'-GTGGTGAAG TCGGCATCAGA-3' (sense) and 5'-AGGTGGAAGAGTGGG TGTCG-3' (antisense). Relative mRNA expression levels were calculated using the $2^{-\Delta \Delta C t}$ method, where GAPDH was used as a reference gene.

Western blot analysis. RF/6A cells were lysed in radioimmunoprecipitation assay lysis buffer supplemented with protease inhibitor. The protein concentration of the lysate was measured using a bicinchoninic protein assay kit (Pierce Biotechnology, Inc., Rockford, IL, USA). Equal quantities of protein $(20 \mu \mathrm{g})$ were subjected to SDS-PAGE, and transferred onto polyvinylidene fluoride membranes (EMD Millipore, Billerica, MA, USA). The membranes were blocked by incubation with $1 \%$ bovine serum albumin for $1 \mathrm{~h}$ at room temperature. The membranes were incubated with a primary rabbit polyclonal antibody against human VEGF (1:2,000; sc-507; Santa Cruz Biotechnology, Inc.) overnight at $4^{\circ} \mathrm{C}$, and subsequently with a goat horseradish peroxidase-conjugated secondary antibody against rabbit IgG (1:500; \#32260; Invitrogen Life Technologies) for $2 \mathrm{~h}$. Immunoreactive bands were visualized using an enhanced chemiluminescence kit.

Cell viability 3-(4,5-dimethylthiazol-2-yl)-2,5-diphenyl tetrazolium bromide (MTT) assay. Cells in the exponential growth phase were plated in 96-well plates at a density of $1 \times 10^{4}$ cells/well in $115 \mu 1$ RPMI 1640 medium. Following shRNA transfection or hypoxia treatment for 24,48 or $72 \mathrm{~h}$, the culture medium was replaced with $115 \mu \mathrm{l}$ FBS-free RPMI 1640 medium containing MTT (Sigma-Aldrich) and incubated at $37^{\circ} \mathrm{C}$ for $4 \mathrm{~h}$. The medium was gently aspirated and $150 \mu \mathrm{l}$ dimethyl sulfoxide (Tianjin Kermel Chemical Reagent Co., Ltd., Tianjin, China) was added, after which the plates were gently shaken for $10 \mathrm{~min}$. Finally, absorbance values were determined at $570 \mathrm{~nm}$ using a Bio-Rad 680 microplate reader (Bio-Rad Laboratories, Inc., Hercules, CA, USA). The inhibitory rate of cell proliferation was calculated as follows: Inhibition rate $(\%)=\left[\left(\right.\right.$ absorbance of $\mathrm{CoCl}_{2}+\mathrm{p}-\mathrm{NC}$ group - absorbance of $\mathrm{CoCl}_{2}+\mathrm{p}$-shRNA group)/absorbance of $\mathrm{CoCl}_{2}+$ p-NC group)] x $100 \%$. 


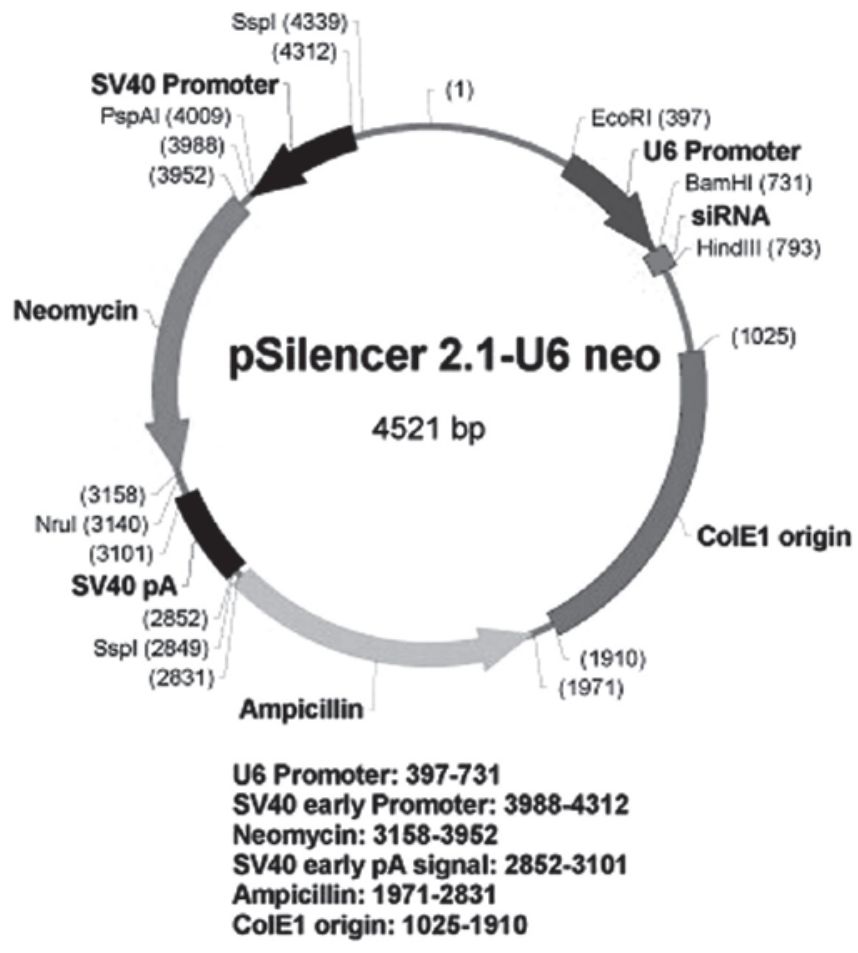

Figure 1. Diagram of the pSilencer 2.1-U6 neo plasmid vector.
GGAT CCCGAAGAGAAGGAGAAGAGAGGT CAAGAGCCTCTCTTCTTCCTTCTCTTCTTTTTT GGAAAAGCTT

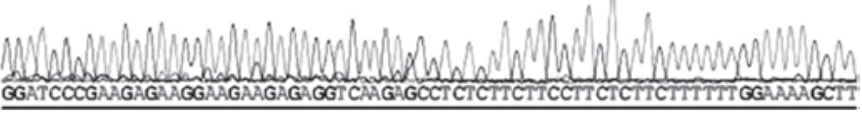

Figure 2. Diagram showing the sequence of the recombinant plasmid Vascular endothelial growth factor short hairpin RNA was designed and synthesized, and the corresponding pSilencer 2.1-U6 neo-shRNA (p-shRNA) expression vector was constructed and identified using enzyme restriction and DNA sequencing. The results revealed that the p-shRNA was constructed successfully, in accordance with the intended design.

Statistical analysis. Continuous data are expressed as the mean \pm standard deviation. One way analysis of variance and the least significant difference test were used for statistical analysis. All statistical tests were two-sided, where $\mathrm{P}<0.05$ was considered to indicate a statistically significant difference. At least three independent experiments were performed in duplicate. SPSS software, version 11.5 for Windows (SPSS, Inc., Chicago, IL, USA), was used for statistical analysis.

\section{Results}

Identification of the recombinant shRNA plasmid vectors. VEGF-targeted shRNA was designed and synthesized, and the corresponding pSilencer 2.1-U6 neo-shRNA expressing vector (p-shRNA) was constructed and identified using enzyme restriction and DNA sequencing. The results indicated that the p-shRNA plasmid was successfully constructed, in accordance with the initial design (Fig. 2).

Effect of VEGF ShRNA on the morphology of RF/6A cells treated with $\mathrm{CoCl}_{2}$. Morphological differences were identified between the cells exposed to $\mathrm{CoCl}_{2}$ or the vehicle for
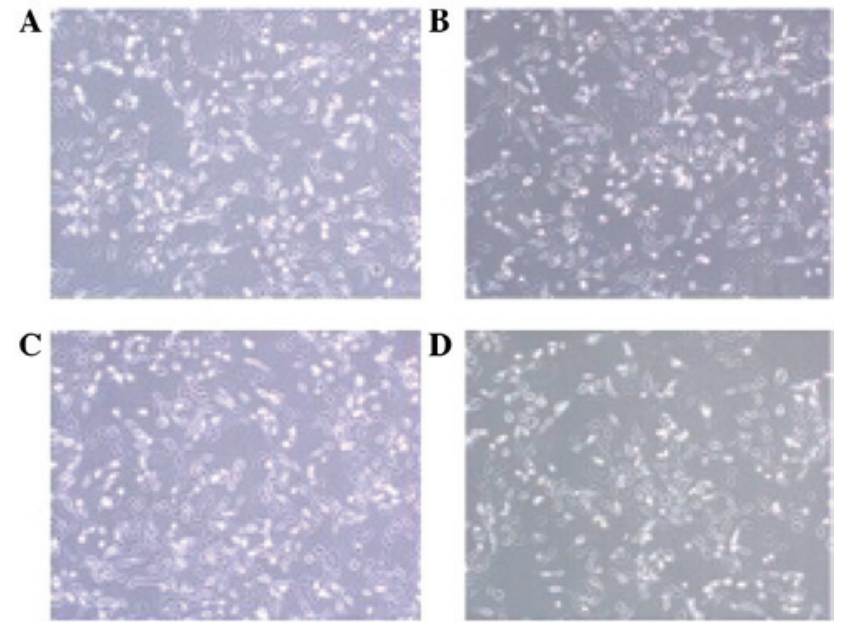

Figure 3. Effect of vascular endothelial growth factor short hairpin RNA (shRNA) on the morphology of RF/6A cells in the (A) normal, (B) $\mathrm{CoCl}_{2}$, (C) $\mathrm{CoCl}_{2}+\mathrm{p}-\mathrm{NC}$ and (D) $\mathrm{CoCl}_{2}+\mathrm{p}$-shRNA groups (magnification, $\mathrm{x} 40$ ) Morphological differences were observed following exposure of the cells to $\mathrm{CoCl}_{2}$ for $24 \mathrm{~h}$. The results indicated that cells in the $\mathrm{CoCl}_{2}$ and $\mathrm{CoCl}_{2}+\mathrm{p}-\mathrm{NC}$ groups exhibited reduced cell connectivity, irregular morphology and reduced thickness compared with the cells in the normal group. However, cells in the $\mathrm{CoCl}_{2}+\mathrm{p}$-shRNA group exhibited reduced morphological alterations compared with the $\mathrm{CoCl}_{2}+\mathrm{p}-\mathrm{NC}$ group. p-NC, pSilencer 2.1-U6 neo-normal control plasmid; p-shRNA, pSilencer 2.1-U6 neo-shRNA plasmid.

$24 \mathrm{~h}$. The results revealed that the cells in the $\mathrm{CoCl}_{2}$ and $\mathrm{CoCl}_{2}+\mathrm{p}-\mathrm{NC}$ groups exhibited reduced cell connectivity, irregular morphology and reduced thickness when compared with the cells in the normal group. However, the cells in the $\mathrm{CoCl}_{2}+\mathrm{p}$-shRNA group exhibited improvements with regard to the morphological alterations when compared with the cells in the $\mathrm{CoCl}_{2}+$ p-NC group (Fig. 3).

Effect of VEGF shRNA on the proliferation of RF/6A cells treated with $\mathrm{CoCl}_{2}$. Proliferation of the RF/6A cells was evaluated following exposure to $\mathrm{CoCl}_{2}$ or normal saline for 24, 48 and $72 \mathrm{~h}$. The results indicated that cell proliferation in the $\mathrm{CoCl}_{2}$ and $\mathrm{CoCl}_{2}+\mathrm{p}-\mathrm{NC}$ groups was enhanced compared with the normal group, and this effect was time-dependent. No statistically significant difference in the rate of cell proliferation was detected between the $\mathrm{CoCl}_{2}$ and $\mathrm{CoCl}_{2}+\mathrm{p}-\mathrm{NC}$ groups. However, the rate of cell proliferation in the $\mathrm{CoCl}_{2}+\mathrm{p}$-shRNA group was significantly attenuated when compared with the $\mathrm{CoCl}_{2}+\mathrm{p}-\mathrm{NC}$ group (Fig. 4A), with inhibition rates of 16,32 and $38 \%$ at 24,48 and $72 \mathrm{~h}$, respectively (Fig. 4B).

Effect of VEGF shRNA on the mRNA and protein expression levels of VEGF in RF/6A cells treated with $\mathrm{CoCl}_{2}$. The VEGF knockdown efficiency of the shRNA in RF/6A cells was confirmed by determining the mRNA and protein expression levels of VEGF following the transfection of the p-NC or p-shRNA vectors into the cells. The results indicated that the transfection of p-NC had no effect on the mRNA and protein expression levels of VEGF (data not shown). However, in the $\mathrm{CoCl}_{2}$ and $\mathrm{CoCl}_{2}+\mathrm{p}$-NC groups, the expression levels of VEGF mRNA (Fig. 5A) and protein (Fig. 5B) were shown to increase when compared with the normal group. No statis- 


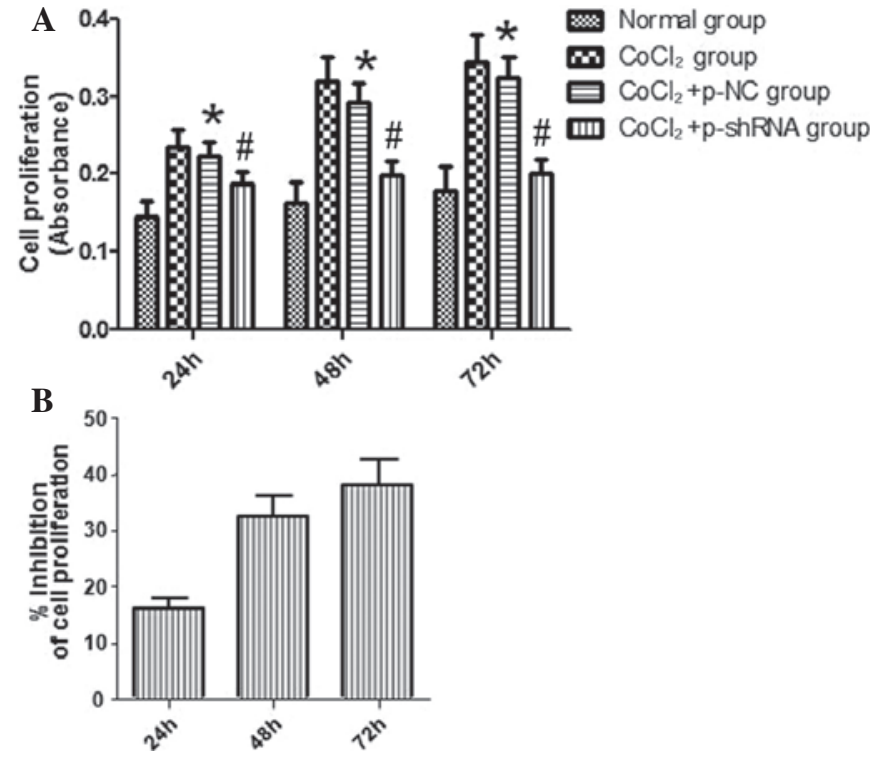

Figure 4. Effect of vascular endothelial growth factor short hairpin RNA (shRNA) on the proliferation of RF/6A cells. The proliferation of RF/6A cells was determined following exposure to $\mathrm{CoCl}_{2}$ for 24,48 and $72 \mathrm{~h}$. (A) Results revealed that $\mathrm{RF} / 6 \mathrm{~A}$ cell proliferation in the $\mathrm{CoCl}_{2}$ and $\mathrm{CoCl}_{2}+\mathrm{p}-\mathrm{NC}$ groups was enhanced in a time-dependent manner, as compared with the normal group. However, the cell proliferation in the $\mathrm{CoCl}_{2}+\mathrm{p}$-shRNA group was significantly inhibited compared with the $\mathrm{CoCl}_{2}+\mathrm{p}-\mathrm{NC}$ group. (B) Inhibition rates of the $\mathrm{CoCl}_{2}+$ p-shRNA group were determined to be 16,32 and $38 \%$ at 24,48 and $72 \mathrm{~h}$, respectively. ${ }^{\mathrm{P}} \mathrm{P}<0.05$, vs. normal group; ${ }^{*} \mathrm{P}<0.05$, vs. $\mathrm{CoCl}_{2}+$ p-NC group. p-NC, pSilencer 2.1-U6 neo-normal control plasmid; p-shRNA, pSilencer 2.1-U6 neo-shRNA plasmid.

tically significant differences were detected in the VEGF mRNA and protein expression levels between the $\mathrm{CoCl}_{2}$ and $\mathrm{CoCl}_{2}+\mathrm{p}$-NC groups. However, the $\mathrm{CoCl}_{2}$-induced increases in the VEGF mRNA and protein expression levels were reduced in the $\mathrm{CoCl}_{2}+\mathrm{p}$-shRNA group, as compared with the $\mathrm{CoCl}_{2}+\mathrm{p}-\mathrm{NC}$ group. Cells in the $\mathrm{CoCl}_{2}+\mathrm{p}$-shRNA group exhibited reduced mRNA and protein expression levels of VEGF (48 and 52\% reductions, respectively) when compared with the $\mathrm{CoCl}_{2}+\mathrm{p}-\mathrm{NC}$ group.

\section{Discussion}

Vascular endothelial cells are able to proliferate and generate new blood vessels in a variety of conditions, including wound healing, inflammation, cancer and retinal or choroidal neovascularization (13). Vascular endothelial cells are the primary targets of VEGF, which is a factor involved in angiogenesis. VEGF binds to receptors on endothelial cells and performs a number of endothelial-associated functions, including the regulation of endothelial proliferation, angiogenesis, vascular permeability and thrombosis. Furthermore, VEGF is able to facilitate the movement of tumor cells into the blood or adjacent tissues, subsequently promoting tumor invasion and metastasis.

Previous studies have indicated that hypoxia is a key regulator and promotor of VEGF expression $(14,15)$. Elevated expression levels of VEGF have been observed in endothelial cells, thereby affecting angiogenesis and development. Firstly, VEGF is a specific mitogen of vascular endothelial cells, which may cause vascular endothelial cells to deform,

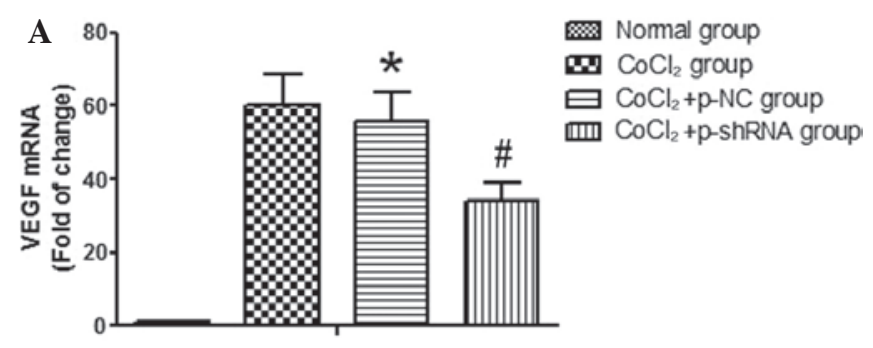

B
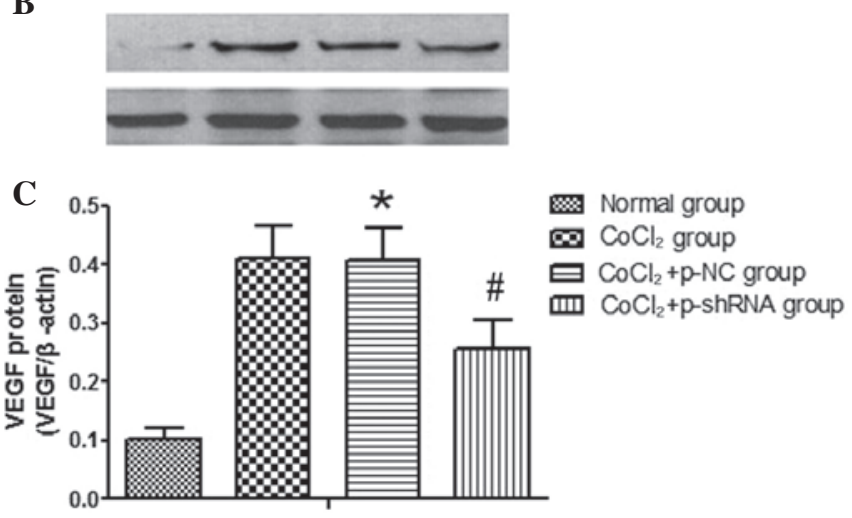

Figure 5. Effect of VEGF shRNA on the mRNA and protein expression levels of VEGF in RF/6A cells. (A) mRNA and (B and C) protein expression levels of VEGF in the $\mathrm{CoCl}_{2}$ and $\mathrm{CoCl}_{2}+\mathrm{p}-\mathrm{NC}$ groups were increased when compared with the normal group. However, the $\mathrm{CoCl}_{2}$-induced increase in VEGF mRNA and protein expression was reduced in the $\mathrm{CoCl}_{2}+\mathrm{p}$-shRNA group when compared with $\mathrm{CoCl}_{2}+\mathrm{p}-\mathrm{NC}$ group. ${ }^{*} \mathrm{P}<0.05$, vs. normal group; ${ }^{\#} \mathrm{P}<0.05$, vs. $\mathrm{CoCl}_{2}+\mathrm{p}-\mathrm{NC}$ group. VEGF, vascular endothelial growth factor; p-NC, pSilencer 2.1-U6 neo-normal control plasmid; p-shRNA, pSilencer 2.1-U6 neo-shRNA plasmid.

migrate, divide and proliferate (16). Secondly, VEGF may induce vascular endothelial cells to increase their vascular permeability, causing vasoconstriction factors, clotting factors, plasma proteins and fibrins to extravasate into the extracellular space. Exosmic fibrins and other proteins, such as fibronectin, are condensed into a fibronectin gel, which provides a matrix component for endothelial cells and other cells, facilitating migration and intrusion, and ultimately converting the cells into vascularized connective tissue (17). In addition, VEGF is a selective mitogen of endothelial cells that is able to stimulate the growth of new blood vessels. Finally, VEGF receptors (VEGFRs) are primarily expressed on endothelial cells, and possess a high affinity for VEGF. The VEGF/VEGFR system is the control center of angiogenesis regulation and may serve a key function in the early stages of angiogenesis. Previous in vitro studies have indicated that VEGF is secreted by retinal microvascular endothelial cells, pericytes and retinal pigment epithelial (RPE) cells $(18,19)$.

Thus, monkey retinal microvascular endothelial cells were employed in the present study to observe the effect of VEGF shRNA on retinal microvascular endothelial cell growth and VEGF mRNA and protein expression levels. The results indicated that the mRNA and protein expression levels of VEGF were significantly enhanced in the cells treated with $\mathrm{CoCl}_{2}$ when compared with those cultured under normoxic conditions, confirming that VEGF expression was oxygen-dependent.

In the present study, a pSilencer 2.1-U6 neo-shRNA recombinant plasmid was constructed, and a hypoxia model 
was established in cultured RF/6A cells via treatment with $\mathrm{CoCl}_{2}$. The morphological differences in the transfected cells were observed and an MTT colorimetric assay was used to detect the effects of the recombinant material on cell survival and growth.

Previous studies have observed that the cell number increases significantly and the cellular morphology becomes irregular under hypoxic conditions. In addition, following VEGF shRNA transfection, the cells appear irregular, with polymerization between the cells reduced and the intercellular gap junctions enlarged $(20,21)$. The present results were consistent with these observations. Due to the compensatory mechanism in response to hypoxic conditions, the cell number is increased and morphological abnormalities become evident. For the VEGF shRNA-transfected cells, the decreased expression of VEGF affects angiogenesis, resulting in cell nutrition disorders and a slowed cell cycle. Therefore, the results of the present study indicate that the hypoxia-induced growth of in vitro-cultured monkey retinal endothelial cells may be inhibited by RNAi.

The results of the present study indicated that cell proliferation was enhanced in the $\mathrm{CoCl}_{2}$ and $\mathrm{CoCl}_{2}+\mathrm{p}-\mathrm{NC}$ groups, while the rate of cell proliferation was decreased in the $\mathrm{CoCl}_{2}+\mathrm{p}$-shRNA group. Furthermore, the growth rate of the cells transfected with VEGF shRNA was significantly reduced compared with the other groups; the growth inhibition rates of the cells were $31.56,41.22$ and $44.68 \%$ following transfection for 24, 48 and $72 \mathrm{~h}$, respectively. The present results are consistent with those of previous studies, and indicate that VEGF shRNA is able to suppress the stimulating effects of VEGF on cell proliferation via a post-transcriptional gene silencing mechanism $(22,23)$. In addition, the present study demonstrated that the p-shRNA VEGF interference plasmid inhibited vascular endothelial cell proliferation, reduced cell growth and impeded angiogenesis.

To date, siRNA for VEGF have been used in the treatment of ocular neovascularization. Murata et al (24) reported that the mRNA expression levels of VEGF in human RPE cells were significantly reduced following transfection with VEGF-targeting siRNA. Specific sequences were designed to bind to the VEGF promoter, and siRNA targeting the intended gene was transcribed and synthesized by RNA polymerase in vitro, and appeared to efficiently and specifically inhibit VEGF expression in human RPE cells (25). Xia et al (26) transfected human umbilical vein endothelial cells with VEGF-165 siRNA, and observed that VEGF mRNA and protein expression levels were decreased in the VEGF-165 siRNA-transfected cells, as compared with the control cells.

The effects of RNAi at a molecular level may be determined by evaluating the mRNA and protein expression levels. In the present study, the mRNA expression level of VEGF was reduced in the normoxia cells, while expression was significantly upregulated in the $\mathrm{CoCl}_{2}$ and $\mathrm{CoCl}_{2}+\mathrm{p}-\mathrm{NC}$ groups when compared with the normal group. No statistically significant difference in VEGF mRNA expression was detected between the $\mathrm{CoCl}_{2}$ and $\mathrm{CoCl}_{2}+\mathrm{p}-\mathrm{NC}$ groups. Although VEGF expression $\mathrm{n}$ the $\mathrm{CoCl}_{2}+\mathrm{p}$-shRNA group remained significantly increased compared with the normoxia group $(\mathrm{P}<0.05)$, the level of VEGF mRNA expression was reduced compared with the $\mathrm{CoCl}_{2}$ group, indicating that VEGF shRNA was able to suppress the expression of VEGF. Furthermore, the level of VEGF protein expression was detected using western blot analysis, and the results indicated that the expression levels of VEGF protein were in accordance with the levels of mRNA expression.

In conclusion, the results of the present study demonstrated that the targeted knockdown of VEGF inhibited the proliferation of vascular endothelial cells under hypoxic conditions, which may be effective for the treatment of retinal neovascularization diseases.

\section{Acknowledgements}

The study was supported by a grant from the Tianjin Science and Technology Committee Foundation (no. 06YFJMJC07200).

\section{References}

1. Heldin $\mathrm{CH}$ : Development possible clinical use of antagonists for PDGF and TGF-beta. Ups J Med Sci 109: 165-178, 2004.

2. Lee YM, Bae MH, Lee OH, et al: Synergistic induction of in vivo angiogenesis by the combination of insulin-like growth factor-II and epidermal growth factor. Oncol Rep 12: 843-848, 2004.

3. Cantón A, Burgos R, Hernández C, et al: Hepatocyte growth factor in vitreous and serum from patients with proliferative diabetic retinopathy. Br J Ophthalmol 84: 732-735, 2000.

4. Du S, Wang S, Wu Q, Hu J and Li T: Decorin inhibits angiogenic potential of choroid-retinal endothelial cells by downregulating hypoxia-induced Met, Rac1, HIF-1 $\alpha$ and VEGF expression in cocultured retinal pigment epithelial cells. Exp Eye Res 116: 151-160, 2013.

5. Frank RN: Diabetic retinopathy. N Engl J Med 350: 48-58, 2004.

6. Ozaki H, Yu AY, Della N, et al: Hypoxia inducible factor-1 alpha is increased in ischemic retina: Temporal and spatial correlation with VEGF expression. Invest Ophthalmol Vis Sci 40: 182-189, 1999.

7. Willett CG, Boucher Y, di Tomaso E, et al: Direct evidence that the VEGF-specific antibody bevacizumab has antivascular effects in human rectal cancer. Nat Med 10: 145-147, 2004.

8. Gragoudas ES, Adamis AP, Cunningham et Jr, et al: Pegaptanib for neovascular age-related macular degeneration. $\mathrm{N}$ Engl J Med 351: 2805-2816, 2004.

9. Mongerard-Coulanges M, Migianu-Griffoni E, Lecouvey M and Jolles B: Impact of alendronate and VEGF-antisense combined treatment on highly VEGF-expressing A431 cells. Biochem Pharmacol 77: 1580-1585, 2009.

10. Shuey DJ, MeCallus DE and Giordano T: RNAi: Gene-silencing in therapeutic intervention. Drug Discov Today 7: 1040-1046, 2002.

11. Aravin AA, Klenov MS, Vagin VV, Rozovskiı̌ IaM and Gvozdev VA: Role of double-stranded RNA in eukaryotic gene silencing. Mol Biol (Mosk) 36: 240-251, 2002 (In Russian).

12. Stewart SA, Dykxhoorn DM, Palliser D, Mizuno H, Yu EY, An DS, Sabatini DM, Chen IS, Hanh WC, Sharp PA et al: Lentivirus-delivered stable gene silencing by RNAi in primary cells. RNA 9: 493-501, 2003.

13. Itakura J, Ishiwata T, Shen B, Kornmann M and Korc M: Concomitant over-expression of vascular endothelial growth factor and its receptors in pancreatic cancer. Int J Cancer 85: 27-34, 2000.

14. Sharkey AM, Day K, Mcpherson A, Malik S, Licence D, Smith SK and Charnock-Jones DS: Vascular endothelial growth factor expression in human endometrium is regulated by hypoxia. J Clin Endocrinol Metab 85: 402-409, 2000.

15. Shweiki D, Itin A, Soffer D and Keshet E: Vascular endothelial grow th factor induced by hypoxia may mediate hypoxia-initiated angiogenesis. Nature 359: 843-845, 1992.

16. Klagsburn M and D'Amore PA: Vascular endothelial growth factor and its receptors. Cytokine Growth Factor Rev 7: 259-270, 1996.

17. Elahy M, Baindur-Hudson S, Newsholme P and Dass C: Mechanisms of PEDF mediated protection against ROS damage in diabetic retinopathy and neuropathy. J Endocrinol 222: R129-R139, 2014. 
18. Aiello LP, Northrup JM, Keyt BA, Takagi H and Iwamoto MA Hypoxic regulation of vascular endothelial growth factor in retinal cells. Arch Ophthalmol 113: 1538-1544, 1995.

19. Thieme H, Aiello LP, Takagi H, Ferrara N and King GL: Comparative analysis of vascular endothelial growth factor receptors on retinal and aortic vascular endothelial cells. Diabetes 44: 98-103, 1995.

20. Song E, Zhu P, Lee SK, et al: Antibody mediated in vivo delivery of small interfering RNAs via cell-surface receptors. Nat Biotechnol 23: 709-717, 2005.

21. Jia RB, Fan XQ, Wang XL, Zhang XQ, Zhang P and Lu J: Inhibition of VEGF expression by plasmid-based RNA interference in the retinoblastoma cells. Zhonghua Yan Ke Za Zhi 43: 493-498, 2007 (In Chinese).

22. Wang J, Shi YQ, Yi J, et al: Suppression of growth of pancreatic cancer cell and expression of vascular endothelial growth factor by gene silencing with RNA interference. J Dig Dis 9: 228-237, 2008.
23. Shen J, Yang X, Xiao WH, Hackett SF, Sato Y and Campochiaro PA: Vasohibin is up-regulated by VEGF in the retina and suppresses VEGF receptor 2 and retinal neovascularization. FASEB J 20: 723-725, 2006.

24. Murata M, Takanmi T, Shimizu S, et al: Inhibition of ocular angiogenesis by diced small interfering RNAs (siRNAs) specific to vascular endothelial growth factor (VEGF). Curr Eye Res 31:171-180, 2006.

25. Cai CM, Sun BC and Liu XY: Short hairpin RNA targeting vascular endothelial grow th factor effectively inhibits expression of vascular endothelial growth factor in human retinal pigment epithelium. Zhonghua Yan Ke Za Zhi 42: 334-337, 2006 (In Chinese).

26. Xia XB, Xiong SQ, Song WT, Luo J, Wang YK and Zhou RR: Inhibition of retinal neovascularization by siRNA targeting VEGF (165). Mol Vis 14: 1965-1973, 2008. 